\title{
The Leser-Trelat sign is a associated with acute myeloid leukemia
}

\author{
Irfan Yavasoglu • Gurhan Kadikoylu • Zahit Bolaman
}

Received: 25 July 2010 / Accepted: 30 July 2010 / Published online: 12 August 2010

(C) Springer-Verlag 2010

\section{Dear Editor,}

A 69-year-old male was admitted with fatigue. His physical examination was normal except that he was pallor. Dermatologic examination revealed multiple eruptive seborrheic keratoses, which he reported had developed over the previous 2 to 3 years (Fig. $1 \mathrm{a}-\mathrm{b}$ ). WBC was $1.9 \times 10^{9} / \mathrm{L}$, hemoglobin $6.4 \mathrm{~g} / \mathrm{dl}$, hematocrit $19.3 \%$, and platelet count $18 \times 10^{9} / \mathrm{L}$. There were blastic cells on peripheral smear and bone barrow aspiration. Bone marrow aspiration revealed hypercellular particles with erythropoiesis and megakaryopoiesis being depressed. The differential counts revealed blasts at $76 \%$, promyelocytes $2 \%$, myelocytes $12 \%$, metamyelocytes $4 \%$, and neutrophils $6 \%$. Dysgranulopoiesis and hypolobation was seen in the granulocytic series. Acute myeloid leukemia with multilineage dysplasia according to WHO classification (AML-M1 according to FAB) was diagnosed after bone marrow biopsy and flow cytometry. The LeserTrelat sign is an eruptive appearance or increase in itchy multiple seborrheic keratoses. This process occurs in a short

We did not receive any financial support. And this study has not been published in any journal.

I. Yavasoglu $(\bowtie) \cdot G$. Kadikoylu $\cdot$ Z. Bolaman Division of Hematology,

Adnan Menderes University Medical Faculty, Aydin, Turkey

e-mail: dr_yavas@yahoo.com

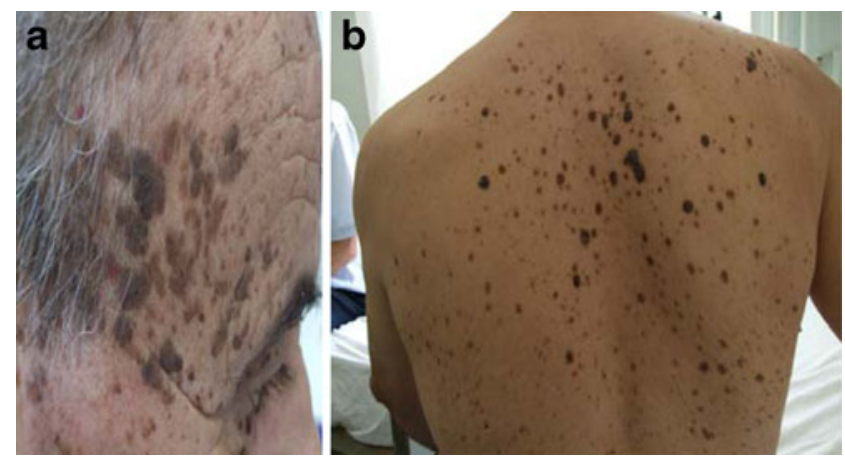

Fig. 1 Multiple eruptive seborrheic keratoses

period of time, and is sign of internal malignancy. The cutaneous findings were consistent with the diagnosis of the Leser-Trelat sign, which is usually associated with gastrointestinal adenocarcinoma. This sign is a controversial physical finding, however, since seborrheic keratoses are common with aging (except sudden appearance, rapid increase in size and number). Induction chemotherapy with mitoxantrone $10 \mathrm{mg} / \mathrm{m}^{2}$ IV over $30 \mathrm{~min}$ on days $1-3$ and cytosine arabinoside $100 \mathrm{mg} / \mathrm{m}^{2}$ IV over 30 min every $12 \mathrm{~h}$ on days $1-7$ was initiated. Now, he is alive and in remission for 3 months. But these lesions remained unchanged. To our knowledge, this is the first report of an association of the Leser-Trelat sign with acute myeloid leukemia. 